\title{
The Importance of Health in Promoting Employability in the East Midlands
}

\author{
by Vanessa Beck and Martin Quinn \\ University of Leicester
}

Sociological Research Online, 16 (1) 8
<http://www. socresonline.org.uk/16/1/8.html>
10.5153/sro.2248

Received: 9 Nov 2009 Accepted: 15 Dec 2010 Published: 28 Feb 2011

\begin{abstract}
This paper analyses the relationship between health and employability in the context of the East Midlands, a high employment region with a history of manufacturing and coal mining, though both sectors' importance has declined due to considerable industrial restructuring. It is argued that the health of the unemployed and economically inactive cannot be considered without an understanding of such contextual factors. Gender, age, the socio-economic context and other external factors are key to the complex relationship between health and employability. Within a broad framework of employability, health is not merely a personal characteristic. The paper argues for more qualitative research into employability and health to establish what factors influence the relationship.
\end{abstract}

\section{Keywords: Employability, Health, Economic In-/activity, Employment, Unemployment}

\section{Introduction}

1.1 The relationship between health and economic activity has received a good deal of attention from academics and policy makers. Reports on the relationship between health and unemployment (Freud, 2007, Black, 2008 and Marmot, 2010) resulted, for example, in headline news that, at £100bn, ill health costs the economy the equivalent of running the NHS for one year (BBC, 2008). The reports sparked discussion about the tightening of eligibility conditions for unemployment benefits (Wintour, 2008) and have tended to emphasise individual responsibility for economic in-/activity and related health issues (cf McQuaid and Lindsay, 2005, Houston and Lindsay, 2009). The new coalition government has set out 'radical welfare reforms' that are likely to see a curtailment of welfare and stronger workfare measures, reinforcing the message that individuals' choices are a key problem. At the international level, the OECD (2008) reports that governments are spending twice as much on illness and disability as on unemployment benefits and warned that this strategy could prove to be costly in the current economic climate as most individuals who are moved onto disability benefits never work again.

1.2 For a large group of people who are considered to have health 'issues', working or not working is not a straightforward choice, as contextual factors, including the economic structure or personal circumstances, limit their options. Debates on health and employment are not always based on clear understandings of the relationships between economic, social and individual factors: what does their interaction mean for different groups of people? And what is the impact of local and regional specificities? It can be argued that the social and contextual aspects of the relationship between health and employment are crucial, as they offer a conception of health as socially embedded (compare Herod et al., 2007). It has already been shown that health and socio-economic status interrelate (Adda et al., 2003) and the ongoing industrial restructuring in the East Midlands offers insights into the change and continuity of such contexts for the relationship between health and employability. The current economic climate provides added incentives to reinvestigate the relationship between health and economic activity. In the East Midlands, unemployment figures have increased (see the section on the unemployed below) and negative health implications of unemployment are well established (Warr, 1987). Further factors contributing to the topicality of this issue are specific to the region.

1.3 The East Midlands is a particularly interesting region to research the relationship between health and employability because it has been (stereo-)typed as a low-skill/low pay economy (Felstead et al., 2002), linking the politics of space with the politics of health. Low-skilled and low pay jobs are often equated with low quality of work (see Gallie, 2007) and with neqative effects for health. Within the UK, the reqion has the 
second highest proportion of people in the workforce with no qualifications and the qualification levels most appropriate for jobs held by East Midlands residents are either 'no qualifications' or qualifications at Level 4 (EMDA, 2006a/b). Level 4 qualifications require analysis of a high level of information and knowledge and are appropriate for those in technical and professional jobs, and/or managing and developing others (Directgov, 2010). The two types of skill demands indicate the division between traditional industries and newer economical developments. Traditionally, the East Midlands relied on manufacturing, especially hosiery and shoemaking, and the coal mines in the north of the region. Industrial restructuring has led to the decline of these industries with 300,000 textiles jobs lost in the last quarter of the 20th century (Quinn, 2001). Business services, wholesaling and construction now make the highest contributions to regional GVA (EMDA, 2006a). Our analysis shows little spatial overlap of decline and new growth (see also Beatty et al., 2009), meaning that in many cases there are few job opportunities for those who previously worked in the traditional industries. We will consider the implications of these sub-regional differences for health.

1.4 This brief outline of developments in the East Midlands suggests why health might be an important aspect of employability in the region. LFS data shows that the particular health problems reported in the region do not differ significantly from the UK as a whole with heart (14.4\%), back and neck (13.6\%), and chest and breathing problems (14.1\%) being the most common. Regional differentiations are not necessarily visible in aggregate statistics. For example, looking after children (especially for women) and having a disability or suffering ill-health (more significant for men) top the list of obstacles to employment (Wiseman and Parry, 2007). Older respondents, who are more likely to have worked in traditional industries, are more likely to be restricted by ill health or physical problems $(14 \%$ of $45+$ according to LFS data). Arguably, an interpretation of these results - though they are not surprising observations - needs to be made against the background of the high employment, low skill, low pay economy of the East Midlands and the ongoing restructuring of its manufacturing tradition.

1.5 This paper explores the relationship between health (both physical and mental) and employability, which in itself is a divisive term which will be discussed in the next section. Following recent policy focus on the inactive and unemployed, the relationships between health and employability is examined for these two groups who may have exited the labour market due to health issues and may face barriers to reemployment for the same reason. This paper argues that regional and societal characteristics are crucial in determining the long-term health of these diverse groups of individuals and their participation in the labour market, though we require more detailed evidence of how these factors interrelate. As the next section suggests, by utilising a broad definition of employability, we are able to consider how health has an effect as an individual factor and as part of the social context. Following the discussion of how the concept of employability is utilised, a section on methods explores the approach taken in this research. The presentation of results is divided into three sections. First, there is a discussion on the extent to which health is a problem for the workforce in the East Midlands. It is then considered in detail what the impact of health is on the employability of the unemployed and economically inactive. Finally, some conclusions are offered.

\section{Health and employability}

2.1 There is an established body of literature relating economic in-/activity to health or poor health (see Warr, 1987; Bellaby and Bellaby, 1999). Social environmental approaches to the study of employment and unemployment, for example, see both manifest functions (pay) and latent functions of employment - that is time management, social contact, structure and meaningful activity - as beneficial to wellbeing. When these positive effects of employment are withdrawn via redundancy or economic inactivity, there is a negative impact on individuals' health (Creed and Bartrum, 2006). Implications of a loss of employment can be wide ranging and may include increased alcohol consumption, cigarette smoking and body weight (Montgomery et al., 1996). Higher levels of cardiovascular diseases (Weber and Lehnert, 1997), suicide attempts (Beautrais et al., 1998) and marital dissolution (Hansen, 2005) are common amongst the unemployed. A further effect of, especially long-term, unemployment, is that individuals find it difficult to reenter the labour market, due to actual or perceived reduction in employability. There is some consensus that work is generally good for health and wellbeing (Waddell and Burton, 2006) and there are indications that the relationship is reciprocal and causal: healthy individuals are more likely to seek, obtain and remain in employment ('healthy worker effect') whilst work can have a valuable social role and beneficial consequences for health ('social causation hypothesis') (Adelmann et al., 1990). However, there is a negative aspect to this relationship in that unhealthy individuals are more likely to be unemployed or economically inactive, and work can be stressful and have negative implications for health. At the European level, stress is the most common work-related health symptom which affects 22 percent of workers (Parent-Thirion et al., 2007) and in the UK, this symptom was experienced by one in three of those claiming Incapacity Benefit (IB) (DH, 2006).

2.2 In the context of successive governments' attempts to reduce the numbers of IB recipients and in the current climate of austerity measures, there is a renewed emphasis on employability as an individual characteristic. The UK Commission for Employment and Skills (UKCES, 2009, 3) are specifically concerned with "the set of basic/generic skills and attitudinal/behavioural characteristics that are believed to be essential for individuals to secure and sustain employment, and also to progress in the workplace" and they highlight "increasing confidence levels" and "building awareness of the importance of soft skills and self presentation in securing and maintaining a job" (ibid, 31) as useful aspects of delivering training programmes. Whilst these are important issues to consider when supporting individuals outside of the labour market, they suggest a partial view of employability. In the East Midlands, the Regional Economic Strategy (RES) aim of moving "more people into better jobs in growing businesses" at least balances the focus on individuals (and developing their skill levels) with supply side priorities (stimulating business demand for skills) (EMDA, 2006b, 55/6, see also EMDA 2009). Moreover, the RES states that ill health as a barrier to employability will be addressed, though it is less clear how either of these aims will be achieved or what the relationships between 'good jobs', ill health and employability are. 
2.3 Employability is thus a widely-used but poorly defined concept. It is generally understood to refer to individuals' ability to obtain and retain employment but, as McQuaid and Lindsay (2005) clearly outline, the majority of interpretations are supply side focused. Within this context, employability can be considered part of an individualisation agenda where employees and jobseekers are responsible for their employability skills and attributes, including health, irrespective of the job opportunities that may or may not be available and independent of the education and training opportunities offered. There has been concern that with "a work ethic culture which holds individuals responsible for their own fate and downplays the importance of societal factors such as lack of employment opportunities and the selectivity of labour markets" (Daguerre, 2004, 53/4) it might be difficult for government to reach their aim and reverse the increase in benefit claimants (cf. Fothergill and Wilson, 2007, Houston and Lindsay, 2009), especially given the changed economic circumstances in the UK. A side-effect of an individualised approach is that health or illness becomes a personal risk rather than a societal concern.

2.4 A definition of employability more in line with the social environmental approach to employment and unemployment would take into consideration factors beyond the individual sphere. McQuaid and Lindsay (2005) suggest a broad employability framework which includes individual factors (skills and attributes, demographic characteristics, health and wellbeing, job seeking, adaptability and mobility), personal circumstances (household, work culture, access to resources) and external factors (demanding and enabling factors). The comprehensive list of factors considered in the broad employability framework provides a more rounded consideration of what employability is. Moreover, as McQuaid and Lindsay (2005, 208) state: "[o]f fundamental importance are the interactions between each of the components." The broad framework cannot consider the inter-relationships of factors, nor does it explain how the various factors influence overall employability. Whilst the 'health and wellbeing' category, for example, includes health (current physical / mental health, medical history, psychological wellbeing) and disability (nature and extent of: physical / mental / learning disability), there is no indication at which point health contributes to or hinders employability. McQuaid and Lindsay (2005) recognise that employment can contribute to good health but, within the context of the overall framework, cannot explore the relationship between health and employability.

2.5 An added, complicating factor is that 'poor health' and 'wellbeing' could include a vast range of conditions. According to the World Health Organisation (WHO, 1948), health is "a state of complete physical, mental and social wellbeing and not merely the absence of disease or infirmity". The definition suggests the breadth of issues that should be considered, whilst it questionable to what extent such levels of health are attainable. The most significant health problems to affect sickness absence, long-term incapacity and early retirement are said to be mild to moderate mental health issues, musculoskeletal and cardio-respiratory conditions (Waddell and Burton, 2006), though they tend to be difficult to measure and are 'essentially subjective' (ibid, 3). Individual contexts and perceptions thus seem to have a considerable influence on the extent to which and ways in which health impacts on employability. In addition, working environments and conditions as well as individuals' attachment to employment need to be considered as factors influencing the relationship between health and employability.

2.6 As employability and health are poorly defined and/or broad concepts, it is difficult to pin down their exact relationship. The picture is clouded by numerous variances in individual situations: working environment, employment status and individuals' values and attachment to the labour market. There are strong indications that the working environment and conditions of employment are important for individuals with different employment status. Control and autonomy on the part of a worker, for example, are seen as improving wellbeing at work (Wood, 2008), whereas job insecurity, and reduced wellbeing have been considered as predictors for later unemployment (Bildt and Michelsen, 2003). Yet, re-employment can lead to improved wellbeing. It has been shown (Strandh, 2000), that the type of exit route from unemployment into employment is crucial, again highlighting the importance of the type and conditions of employment (Leana and Feldman, 1995; Wanberg, 1995). There is an underlying hypothesis that individuals with health problems tend to lose their jobs more than healthy individuals and are less likely to be re-employed. Good health in itself may be a determinant of long term employment (Virtanen et al., 2006). Other studies indicate that baseline health does not predict employment status (Vesalainen and Vuori, 1999) though this particular study did suggest that psychological distress increases the perceived need for adjustment in a new job. Evidence on causal relationships between health and employability is complex and inconsistent. It is not only employment status (employed, unemployed, inactive) that influences health but also working conditions and the means by which re-integration into work is achieved and how redundancy is implemented.

2.7 A further aspect to be considered is the individual's attachment to employment and the subsequent potential benefit derived from employment. Warr and Jackson (1985) found that stronger attachment to employment leads to more negative side effects of unemployment and, consequently, it must be assumed that stronger attachment to employment results in more beneficial side effects of employment. Although attachment to work weakens with length of unemployment, the unemployed tend to display stronger work attachment than the employed (Gallie and Vogler, 1994). In regional terms this means that in parts of the East Midlands where there are higher unemployment and IB rates (e.g. Chesterfield), there is likely to be more detachment from the labour market, despite long work histories, than in areas with low unemployment and IB rates (e.g. Northampton) (Hasluck and Green, 2007). The indication is that there are different strengths of relationships between health and employability. Moreover, while higher qualifications and status tends to be correlated to higher attachment to work, studies with re-employed executives showed their attitudes to employment to become worse if re-employed in jobs with less pay, status and use of their skills (Feldman et al., 2002), reinforcing the importance of working environments and conditions.

2.8 This paper aims to add further dimensions to this complex set of inter-relationships by considering some social and regional factors that influence the relationship between health and employability. In particular, the main body of the paper will look in more detail at this relationship for the unemployed and economically inactive. Prior to this, the methodological approach to the research undertaken will be 
outlined.

\section{Methodology}

3.1 This paper is based on research undertaken between December 2007 and April 2008 for Emda, the East Midlands Development Agency (Beck et al., 2008). It considered the relationship between mental and physical health and employability. The project required statistical and literature reviews to assess the linkages between health and employability, labour market and general economic performance. The overall approach utilised was interdisciplinary in nature to gain an overview of the relationship between health and employability. Literature from a range of relevant areas was considered: economics; sociology of work and skills; (occupational) psychology; social policy; (human) geography; and the health sciences. The challenge of this project was to combine social science and health science data, quantitative analysis and reports on qualitative research to gain an understanding of the numerous factors that affect health and therefore also employment.

3.2 In addition to the literature, key statistical data was utilised, above all the Labour Force Survey (LFS). Only where the LFS did not provide the specific questions required were other statistical sources employed. A problem in bringing data from different sources together is compatibility. As is shown in the next section, some data provide contradictory results. However, as results presented in this paper are mainly derived from one dataset, findings should be consistent. The LFS is a large scale government survey carried out 4 times a year by the Office of National Statistics. The survey works using 'sweeps' of around 20,000 people who will be interviewed for five consecutive quarters to gather longer term, consistent data and in any one quarter there are five different sweeps participating in the survey. This leads to an overall sample of more than 100,000 people. To counter seasonal variation and make the sample bigger and more reliable, the last four sweeps of the LFS were combined to give a picture based on twelve months worth of data. An alternative approach would have been to use the annual LFS survey but this does not contain detailed health questions so would not have given us the same amount of detail. The total UK working age population of our sample was 280,639. Split by Government Office Regions, the working age sample for the East Midlands was 21,387 people. For the benefits data just one sweep of the LFS rather than four were used as the survey was undergoing a change in the way it recorded benefits data to bring it in line with Eurostat. The regional ONS team also gave us access to sub-regional data not normally publicly available, which allowed us to look in more detail at differences below Government Office Region boundaries. This data only provides indicative results. In some cases it was useful to provide a UK figure to show how the region compared to the national averages, however this was not done for all tables as in some cases (for example inactivity by last occupation) a UK figure would not have added to the analysis.

3.3 As the use of the LFS suggests, the research was limited to utilising existing data, restricting the ability to explain some of the findings. Qualitative research into the relationship between health and employability would be required to explore the indicative findings presented in the following. Further analysis should also be undertaken to understand how the current economic climate will change our findings, as it is likely that austerity measures and the possible increase in unemployment figures will add further pressure on individuals outside of the labour market.

3.4 Having outlined the approach and methods, headline statistics for the East Midlands are presented to help explore the importance of considering health in relation to individuals' employability.

\section{How much does ill health influence the East Midlands labour market?}

4.1 Wiseman and Parry (2007) report that of the respondents to the East Midlands Household Survey in 2006 , only 8 percent had a disability or suffered ill-health that restricted the type of work they were able to do. However, other statistical sources providing information on health and the labour market produce different results. The following graph shows that responses to the Health Survey in the East Midlands indicate that 23 percent have a limiting longstanding illness with a further 19 percent who have a nonlimiting longstanding illness. The results of the Health Survey might have been influenced by the 2005 survey's inclusion of an older adult booster sample as both the Health Survey and Household Survey ask very similar questions. Nevertheless, this raises questions as to the reliability and compatibility of available data, which are partially responsible for the lack of clarity regarding the interrelationship between health and employability. This makes it all the more important to consider regional and societal details to understand how health influences employability. 


\section{Graph 1: Incidents of Limiting Longstanding Illness}

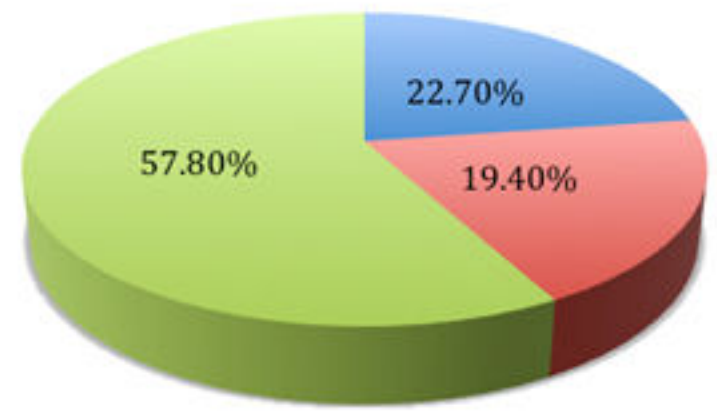

= Limiting LI

Non limiting LI

No LI

Source: Own calculations from Health Survey for England 2005, n = working age respondents in the East Midlands

4.2 Both the East Midlands Household Survey 2006 and the LFS show that the proportion of East Midlands respondents that have a limiting illness or disability is lower than the UK average. This might suggest that, at first sight, there are no particular issues with health and employability in the East Midlands. Other results similarly reflect general trends. Splitting the LFS sample by age shows that health problems are more likely to limit activity the older an individual gets: 40.8 percent of 16-19 year olds said that their health problem limited their activity compared to 60.0 percent of 55-59 year olds. A deterioration of health with age is to be expected and is likely to have an increasing impact on the ability to work, though closer attention needs to be paid to how health impacts on individuals. Graph 2 shows the reported impact of health problems on the work capability of respondents. A little over half of all respondents said that their health problems had an effect on the kind of work they were able to do while more than 40 percent said they affected the amount of work they could do. This differentiation is relevant considering the types of skill demand (mainly low skills) in the East Midlands, and the efficiency of workers. The amount of work that can be undertaken may affect all jobs but the kind of work to be undertaken may be more important with regard to heavy manual or stressful jobs. Once again there is little difference between the reported figures for the East Midlands and the UK.

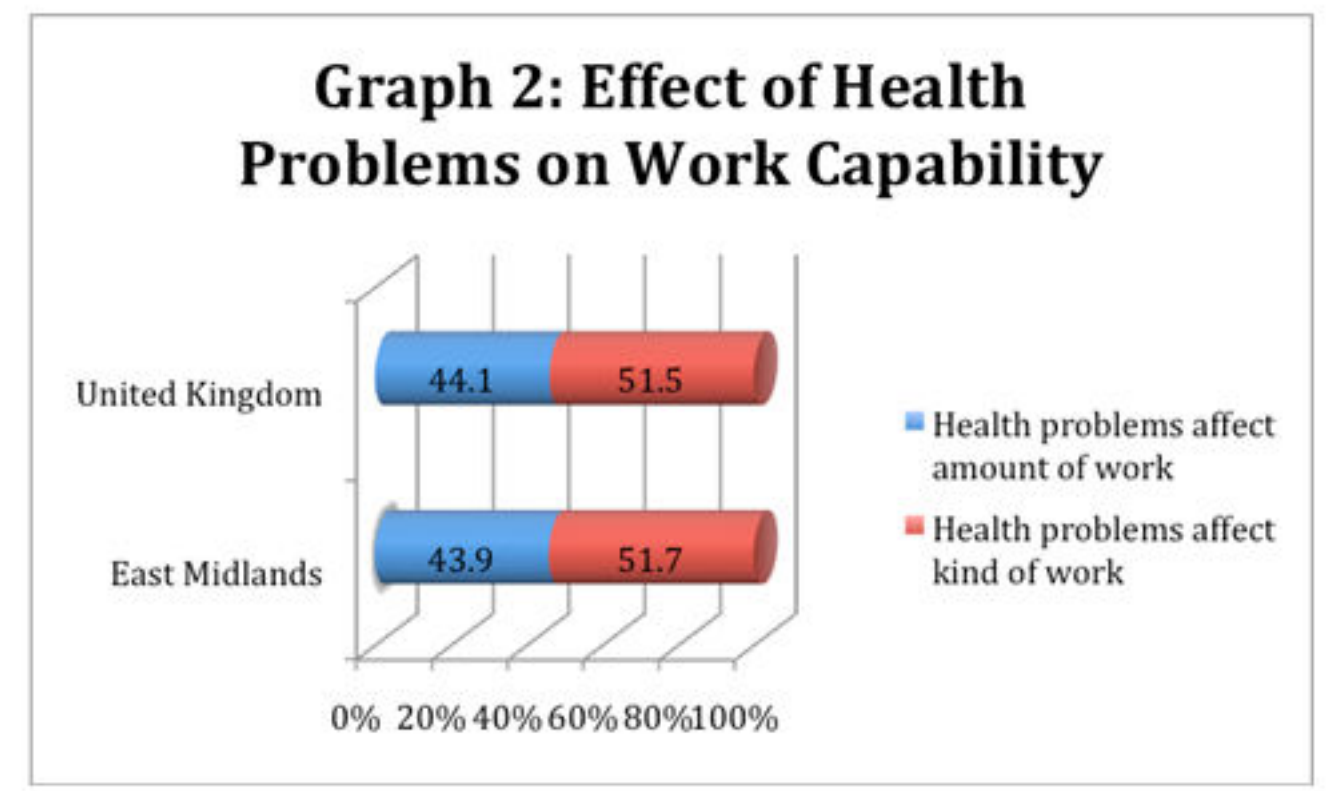

Source: Labour Force Survey October 2006 - September 2007 (Working Age Population only)

4.3 These headline statistics show that poor health has varied effects on a considerable proportion of the workforce within the East Midlands. There are strong indications that age and the type of job and working conditions will affect the ability to work of individuals who have health issues and this might create 
problems in the specific context of the East Midlands. However, the data also confirms that the East Midlands is a high employment region which is reflected in slightly high employment rates and lower inactivity rates (see table 1 below).

Table 1: Economic Activity of Working Age Population (in \%)

\begin{tabular}{|l|l|l|}
\hline & East Midlands & United Kingdom \\
\hline Employee & 66.6 & 64.8 \\
\hline Self-employed & 9.3 & 9.5 \\
\hline Government employment \& training programmes & 0.3 & 0.3 \\
\hline Unpaid family worker & 0.1 & 0.2 \\
\hline ILO Unemployed & 4.2 & 4.1 \\
\hline Inactive due to sickness/ injury/ disability & 5.7 & 6.3 \\
\hline Other inactive & 13.8 & 14.8 \\
\hline
\end{tabular}

Source: Labour Force Survey October 2006 - September 2007 (Working Age Population only)

\section{Unemployment}

5.1 Unemployment could in itself be an indicator for the effect health has on the labour market in that illness may have resulted in redundancy and/or prevented reemployment. Following a sharp decline in the 1990s, unemployment levels had been stabilising in the East Midlands (EMDA, 2006a) prior to the recession. A claimant-based count (JSA) for August 2010 shows that the East Midlands still has lower unemployment $(3.4 \%)$ than the UK (3.6\%) though the East Midlands ILO unemployment rate for the period January 09 to December $09(7.4 \%)$ has increased on the previous year (5.9\%) (LSR, 2010).

5.2 Official unemployment statistics have been criticised because they do not include the ILO unemployed; participants on government schemes without a contract of employment; and a modelled estimate of the proportion of sickness claimants and the early retired who could reasonably be expected to be working in a fully employed economy (see Beatty et al., 2002). When considering such a 'real' unemployment rate, the initially clear cut picture of high unemployment in the north of the region (especially Mansfield and Bolsover) and low unemployment in southern sections (e.g. Northampton and Kettering) can be differentiated. Whereas the northern former coalfields tend to have higher unemployment, industrial towns (e.g. Amber Valley) fare well. It is thus not only the old industrial areas that fare poorly. The city of Nottingham has one of the highest real unemployment rates but, as an industrial town in the south, Corby also has a relatively high real unemployment rate. The rough picture of the region's spread of unemployment seems to be related not only to employability but also to health and/or potential illness. Findings emerging from the work of the Coalfield Communities Campaign show, for example, that life expectancy in Shirebrook, a former colliery town in Derbyshire with high unemployment, is 17 years less when compared to the most affluent areas of that county (Wilson, 2007). Regional variation in incidents of ill health amongst the unemployed seem to be linked to the local industrial or economic structure. A further influencing factor, however, is personal circumstances.

5.3 Table 2 breaks down types of benefits claimed by the working age population. Proportionally more people claimed benefits related to sickness or disability than the UK average despite the earlier finding that less people in the East Midlands were inactive due to their own ill health. The reasons for this are outlined in Table 3 concerning the type of sick or disability benefit claimed. There is a higher proportion of people in the region claiming Invalid Care Allowance than for the country as a whole, while the figures for Disability Living Allowance are higher for the UK than for the East Midlands. This may suggest that the East Midlands has a particular issue with ill health affecting more than just the employability of the individual involved, that care provisions are sparse and/or that the industrial structure has led to particular need for care. Based on this data, it can be argued that health is not merely an individual factor influencing employability but that it also becomes part of the personal circumstances (see McQuaid and Lindsay, 2005). Aspects such as household circumstances, including direct caring responsibilities as well as access to resources such as support for care from institutions or family networks will have a considerable impact on the employability of the person with health issues as well as their carers. 
Table 2: Type of Benefits Claimed (\%)

\begin{tabular}{|l|l|l|}
\hline & East Midlands & United Kingdom \\
\hline Unemployment benefit & 4.1 & 4.3 \\
\hline Income support (not as unemployed) & 8.1 & 10.9 \\
\hline Sickness or Disability & 14.4 & 13.2 \\
\hline State Pension & 11.8 & 11.8 \\
\hline Family related benefits (not child benefit) & 0.2 & 0.2 \\
\hline Child benefit & 49.4 & 49.5 \\
\hline Housing benefits & 1.3 & 1.4 \\
\hline Tax credits & 8.7 & 6.9 \\
\hline Other & 1.9 & 1.9 \\
\hline
\end{tabular}

Source: Labour Force Survey July - September 2007 (Working Age Population only)

Table 3: Type of Sick or Disability Benefit Claimed (\%)

\begin{tabular}{|l|l|l|}
\hline & East Midlands & United Kingdom \\
\hline Incapacity benefit & 51.0 & 50.1 \\
\hline Severe disablement allowance & 4.7 & 4.4 \\
\hline Statutory sick pay & 1.8 & 2.1 \\
\hline Invalid care allowance & 10.7 & 7.9 \\
\hline Disability living allowance & 29.7 & 33.0 \\
\hline Attendance Allowance & 1.0 & 0.9 \\
\hline Industrial industry disablement allowance & 1.0 & 1.5 \\
\hline
\end{tabular}

Source: Labour Force Survey July - September 2007 (Working Age Population only)

5.4 Although the East Midlands has unemployment rates that are comparable to the national average, there are indications that illness has an impact on the employability of the unemployed. It is also suggested that factors influencing the employability of an individual are far-reaching and may not be limited to the health of the person themselves but also to the health and care requirements of their carers, relatives and/or friends.

\section{Economic inactivity}

6.1 In this section LFS data is used to build a profile of those respondents from the East Midlands who are economically inactive due to ill health and consider their potential employability. As previously indicated, the LFS analysis shows that age is a factor in inactivity due to ill health with more than half of this group aged over 50 and a fifth over 60 . There is a steady increase in the proportion of the economically inactive by age band from just 1.5 percent of the sample being 16-19 year olds to 14.8 percent aged $60-64$. Interestingly, however, the slightly younger age group of those between 55 and 59 have the highest economically inactive due to ill health rate at 23.3 percent. Individuals with ill health in the older group, i.e. 60 and over might be able to opt for (early) retirement rather than economic inactivity, though it should also be noted that this group contains mainly men and that gender differences play a role in ill health within this 
age group. Given changes in (state) pension age it will be important to monitor whether and/or how these tendencies might develop.

6.2 In addition to the to-be-expected increase in ill health with age, there is a significant group who are inactive because they are looking after a family home. The East Midlands has a reasonably large group of economically inactive carers who could be looking after (young) children, the elderly or long-term ill or disabled individuals. Despite government concern over carers' lack of integration into the labour market, carers find it difficult to combine caring and employment (Arksey and Glendinning, 2007). Caring responsibilities point to the importance of personal circumstances and show that these have implications for labour market participation. A large proportion amongst these carers are likely to be women and this is supported by the gender difference of 10 percent in the incidence of economic inactivity being caused by ill health (44.9\% female, $55.1 \%$ male). There is a common wisdom that 'women are sicker but men die quicker' (Lahelma et al., 1999). In the UK there has been a tendency since the 1970s towards an increase of male economic inactivity and parallel long-term illness (Beatty and Fothergill, 2002, 2007). It could be speculated, however, that women are more likely to work below their potential and thus in occupations and working conditions that may have negative effects on their health (cf. Yeandle, 2008). As suggested below, in the East Midlands, the historical industrial structure may also have an impact. For the East Midlands, no significant impact of ethnicity was found, though it would be interesting to look in more detail at subregional areas, such as the main cities, where the proportion of ethnic minorities is larger.

6.3 When the economically inactive due to ill health sample is split by the sector they worked in for their last job some interesting statistics emerge. More than a quarter of this group in the East Midlands last worked in the manufacturing sector, almost two times as many as the next most frequently cited sector and a long way ahead of sectors in which health can be a considerable problem such as construction. Very few of this group worked in finance, education or public administration, sectors of increasing relevance to the region. This would suggest that past work in manufacturing has led to an increased incident of ill health, and, to follow Beatty and Fothergill's (2000) argument, that it is a combination of health problems and redundancies due to industrial restructuring that is responsible for high rates of economic inactivity, rather than high rates of unemployment.

Table 4: Economically Inactive Due to Ill Health by Industry Sector in Last Job

\begin{tabular}{|l|l|}
\hline & $\%$ \\
\hline Manufacturing & 26.4 \\
\hline Health \& Social work & 14.2 \\
\hline Wholesale, retail \& motor trade & 12.9 \\
\hline Hotels \& restaurants & 10.4 \\
\hline Real estate, renting \& business activities & 7.7 \\
\hline Other community, social \& personal & 6.4 \\
\hline Construction & 6.2 \\
\hline Transport, storage \& communication & 5.9 \\
\hline Public administration \& defence & 4.2 \\
\hline Education & 3.7 \\
\hline Financial intermediation & 1.3 \\
\hline Agriculture \& forestry & 0.3 \\
\hline Mining \& quarrying & 0.3 \\
\hline Private Households & 0.2 \\
\hline
\end{tabular}

Source: Labour Force Survey October 2006 - September 2007 (Working Age Population only)

6.4 Finally, those who are economically inactive due to ill health were analysed by the major occupation group they belonged to in their last job. As can be seen in Table 5 more than one in four of this group of people last worked in the bottom two categories, process plant and machine operatives and elementary occupations with a further one in ten having worked in skilled trade occupations. 
Table 5: Economically Inactive Due to Ill Health by Major Occupation Group in Last

Job

\begin{tabular}{|l|l|}
\hline & $\%$ \\
\hline Managers \& senior of ficials & 8.9 \\
\hline Professional occupations & 4.5 \\
\hline Associate professional and technical & 10.2 \\
\hline Administrative and secretarial & 6.5 \\
\hline Skilled trade occupations & 11.7 \\
\hline Personal service occupations & 9.4 \\
\hline Sales and customer service occupations & 5.0 \\
\hline Process plant and machine operatives & 19.3 \\
\hline Elementary occupations & 24.3 \\
\hline Source: Labour Force Survey October 2006 - September 2007(Working Age Population only)
\end{tabular}

Source: Labour Force Survey October 2006 - September 2007 (Working Age Population only)

6.5 The statistics provide a clear indication that the incident of being economically inactive due to ill health is strongly linked to the last sector worked in, i.e. mainly manufacturing, and the type of work last undertaken, such as elementary occupations, process plant and machine operative. This suggests that external factors, such as the sectoral and occupational structure in a locality and the job openings, play an important role in the relationship between health and employability.

\section{Discussion and conclusions}

7.1 This article has considered the impact health has on employability. The initial discussion showed how these causal relationships are complex and that further qualitative research should address the relationships indicated in our results. Despite this, there are persistent and complex problems. Health issues in the East Midlands have a considerable impact on employment. Depending on the source used around 42 percent of working respondents have a limiting or non-limiting longstanding illness. Health problems impact on how many people are available to the East Midlands economy but also make those that are available less flexible in what work can be undertaken and what hours can be worked. In particular, age and gender are crucial determinants for health status impacting on participation in the labour market. Whilst it may be expected that health deteriorates with age, this does not necessarily have to impact on labour market participation. There is a steady increase of the economically inactive group with age, with the largest group aged between 55 and 59. The fact that societies are growing older due to decreased birth rates and improved medical and care facilities implies that older workers, even those with health issues, are valuable to the labour market (Beck, 2009). A renewed look at working conditions as part of active age management systems is required to ensure that the economy benefits from older workers' skills and experiences.

7.2 It has been suggested that health is part of the social context and the personal circumstances influencing individual's employability. Proportionally more people in the East Midlands claim benefits such as sickness or disability benefits than in the UK as a whole. When breaking down the types of benefit claimed, the East Midlands has slightly higher levels of Incapacity Benefit and especially of Invalid Care Allowance recipients. Health problems thus not only affect the individual directly but also have secondary effects on carers' ability to maintain their employability. Carers are those who look after the ill, and those who are economically inactive because they look after a family home. These secondary effects of poor health and caring explain some of the gender differences in the incidence of being economically inactive due to ill health. It is therefore important for policy makers to consider not only illness but also related (care) needs and social contexts.

7.3 A key factor to emerge from the research is the importance of regional and societal characteristics, that is external factors influencing employability. Considering the economically inactive due to ill health sample, there is evidence for the continuing importance of the manufacturing sector in the East Midlands. Of those who are economically inactive due to ill health, more than a quarter last held a job in that sector. The largest group worked in elementary occupations, closely followed by process plant and machine operatives. These results suggest that work that is characterised by poor working conditions is not only an immediate problem but that it has long-term implications. Poor work tends to correlate with utilitarian work identities of those working in (often) manual, repetitive jobs that provide little in terms of intrinsic job 
satisfaction. Our findings lend further support to arguments for 'good' work (Lindsay, 2005, Sengupta et al, 2009, Mayo, 2009). Regional policy and development actors may struggle to tackle poor health amongst the workforce directly but should consider the relationship between space, employment, and health, for example, by exerting influence over working conditions and the type of employment that is attracted to the region. The historical dominance of manufacturing in the East Midlands shows that regional development is a long-term game that can have considerable effects on workers' health.

7.4 In this review of the data and literature, it has not been possible to clearly determine the direction of causal relationships between health and employability, mainly due to the limitations of the datasets and the quantitative approach. However, further questions have been raised regarding the role of health in individuals' employability. In particular, it has been argued that health is not merely an individual factor but part of the personal circumstances and external factors. There is a need for further, qualitative research into these relationships. Above all, health needs to play a more important role in considerations regarding employment conditions and the development of the regional economy. Given the continued impact that the past industrial structure has on individuals who are economically inactive due to ill health, a long-term approach needs to be taken to ensure that the workforce is in a position to work for as long as possible. Beneficial health effects depend on the nature and quality of work (Waddell and Burton, 2006) though there is insufficient evidence to define the physical and psychosocial characteristics of jobs and workplaces that are 'good' for health. Finally, it is crucial that the social context is taken into account, particularly social gradients in health and regional deprivation. These provisos are especially important given the lack of reliable and compatible data and thus clear evidence regarding the relationship between health and employment.

\section{References}

ADDA J., CHANDOLA T. and MARMOT M. (2003) Socio-economic status and health: causality and pathways. Journal of Econometrics, 112(1), pp. 57-63. [doi:10.1016/S0304-4076(02)00146-X]

ADELMANN P.K., ANTONUCCI T.C., CROHAN S.E. and COLEMAN L.M. (1990) A Causal Analysis of Employment and Health in Midlife Women. Women Health, 16(1), pp. 5-20. [doi:10.1300/J013v16n01_02]

ARKSEY H. and GLENDINNING C. (2007) Combining Work and Care: Carers' Decision-Making in the Context of Competing Policy Pressures. Social Policy \& Administration, 42(1), pp. 1-18.

BBC (2008) III-health 'Costs Economy £100bn'. BBC On-line, 17 March.

BEATTY C., FOTHERGILL S., HOUSTON D. and POWELL R. (2010) Bringing Incapacity Benefit numbers down: to what extent do women need a different approach?, Policy Studies, 31(2), pp. 143-162.

[doi:10.1080/01442870903429603]

BEATTY C. and FOTHERGILL S. (2007) Changes in the Profile of Men Claiming Incapacity Benefit - A Case Study. People, Place \& Policy Online, 1(3), pp. 136-13. [doi:10.3351/ppp.0001.0003.0004]

BEATTY C. and FOTHERGILL S. (2002) Hidden Unemployment Among Men: A Case Study. Regional Studies, 36(8), pp. 811-823. [doi:10.1080/0034340022000012261]

BATTY C. and FOTHERGILL S. (2000) A Theory of Employment, Unemployment and Sickness. Regional Studies, 34(7), pp. 617-630. [doi:10.1080/00343400050178429]

BEATTY C., FOTHERGILL S., GORE T. and GREEN A. (2002) Hidden Unemployment in the East Midlands. Sheffield Hallam University: Centre for Regional Economic and Social Research.

BEAUTRAIS A.L., JOYCE P.R. and MULDER R.T. (1998) Unemployment and Serious Suicide Attempts. Psychological Medicine, 28(1), pp. 209-218. [doi:10.1017/S0033291797005990]

BECK V. (2009) Older Workers - Older Learners: The perspectives of employers in the East Midlands, Leicester: Learning and Skills Council.

BECK, V., QUINN, M., DUNN, A., EDMUNDS OTTER, M., HAMMER, N. and PITCHFORTH, E. (2008) The Economics of Health, Nottingham: East Midlands Development Agency.

BELLABY P. and BELLABY F. (1999) Unemployment and III-health: Local Labour Markets and III-health in Britain 1984-1991. Work, Employment and Society, 13(03), pp. 461-482.

BILDT C. and MICHELSEN H. (2003) Occupational Conditions Exceed the Importance of Non-occupational Conditions and III-health in Explaining Future Unemployment Among Women and Men. Archives of Women's Mental Health, 6(2), pp. 115-126. [doi:10.1007/s00737-002-0177-8]

BLACK C. (2008) Working for a Healthier Tomorrow. London: TSO.

CREED P. and BARTRUM D. (2006) Explanation for Deteriorating Wellbeing in Unemployed People: Specific Unemployment Theories and Beyond. In: Kieselbach, T., Winefield, A. Boyd, C. and Anderson, S. (eds) Unemployment and Health, International and Interdisciplinary Perspectives, Bowen Hills Qld: Australian Academic Press, pp. 1-20.

DAGUERRE A. (2004) Importing Workfare: Policy Transfer of Social and Labour Market Policies from the USA to Britain under New Labour. Social Policy \& Administration, 38(1), pp. 41-56. [doi:10.1111/j.1467- 
DIRECTGOV (2010) Qualifications: what the different levels mean.

<http://www.direct.gov.uk/en/EducationAndLearning/QualificationsExplained/DG_10039017> (accessed 26 February 2010).

DH (2006) End of the 'Prozac Nation' - More Counselling, More Therapy, Less Medication to Treat Depression. <http://www.dh.gov.uk/en/Publicationsandstatistics/pressreleases/DH_4134785>(accessed 10 November 2007).

EMDA (2009) The East Midlands in 2009. Nottingham: East Midlands Development Agency.

EMDA (2006a) The East Midlands in 2006. Nottingham: East Midlands Development Agency.

EMDA (2006b) A Flourishing Region. Regional Economic Strategy for the East Midlands 2006-2020. Nottingham: East Midlands Development Agency.

FELDMAN D.C., LEANA C.R. and BOLINO M.C. (2002) Underemployment and Relative Deprivation Among Re-employed Executives. Journal of Occupational \& Organizational Psychology, 75(4), pp. 453471. [doi:10.1348/096317902321119682]

FELSTEAD, A., QUINN, M. and SUNG, J. (2002) Baseline Labour Market Information for the East Midlands. Nottingham: East Midlands Development Agency.

FOTHERGILL S. and WILSON I. (2007) A Million off Incapacity Benefit: How Achievable is Labour's Target? Cambridge Journal of Economics, 31(6), pp. 1007-1023. [doi:10.1093/cje/bem029]

FREUD D. (2007) Reducing Dependency, Increasing Opportunity: Options for the Future of Welfare to Work. Leeds: Department for Work and Pensions.

GALLIE D. (ed.) (2007) Employment Regimes and the Quality of Work, Oxford University Press.

GALLIE D. and VOGLER C. (1994) Unemployment and Attitudes to Work.In: GALLIE D., MARSH C. and VOGLER C. (eds) Social Change and the Experience of Unemployment. Oxford: Oxford University Press, pp. 115-153.

HANSEN H.T. (2005) Unemployment and Marital Dissolution A Panel Data Study of Norway. European Sociological Review, 21(2), pp. 135-148. [doi:10.1093/esr/jci009]

HASLUCK C. and GREEN A.E. (2007) What Works for Whom?: A Review of Evidence and Meta-analysis for the Department for Work and Pensions. Leeds: Corporate Document Services for the Dept. for Work and Pensions.

HEROD A., RAINNIE A. and McGRATH-CHAMP S. (2007) Working Space: Why Incorporating the Geographical Is Central to Theorizing Work and Employment Practices. Work, Employment and Society, 21(2), pp. 247-264. [doi:10.1177/0950017007076633]

HOUSTON, D. and LINDSAY, C. (2010) Fit for work? Health, employability and challenges for the UK welfare reform agenda. Policy Studies, 31(2), pp. 133-142. [doi:10.1080/01442870903429595]

LAHELMA E., MARTIKAINEN P., RAHKONEN O. and SILVENTOINEN K. (1999) Gender Differences in IIIhealth in Finland: Patterns, Magnitude and Change. Social Science Medicine, 48(1), pp. 7-19. [doi:10.1016/S0277-9536(98)00285-8]

LEANA C.R. and FELDMAN D.C. (1995) Finding New Jobs After a Plant Closing: Antecedents and Outcomes of the Occurrence and Quality of Reemployment. Human Relations, 48(12), pp. 1381-1402. [doi:10.1177/001872679504801201]

LINDSAY C. (2005) 'McJobs', 'good jobs' and skills: job-seekers' attitudes to low-skilled service work, Human Resource Management Journal, 15(2), pp. 50-65. [doi:10.1111/j.1748-8583.2005.tb00146.x]

LSR (2010) Unemployment Bulletin August 2010, Leicestershire Statistics and Research Online, <http://www.Isr-online.org/reports/unemployment_bulletin_August_2010>[accessed 24 September 2010].

MARMOT M. (2010) Fairer Society, Healthy Lives, The Marmot Review, <http://www.marmotreview.org> [accessed 10 September 2010].

MAYO E. (2010) Good Work, Community, Work \& Family, 4(3), pp. 349-353.

MCQUAID R.W. and LINDSAY C. (2005) The Concept of Employability. Urban Studies, 42(2), pp. $197-219$. [doi:10.1080/0042098042000316100]

MONTGOMERY S.M., BARTLEY M.J., COOK D.G. and WADSWORTH M.E. (1996) Health and Social Precursors of Unemployment in Young Men in Great Britain. Journal of Epidemiology \& Community Health, 50(4), pp. 415-422. [doi:10.1136/jech.50.4.415]

OECD (2008) The OECD "Sickness, Disability and Work" project.

<http://www.oecd.org/document/20/0,3343,en_2649_33933_38887124_1_1_1_1,00.html> (accessed 22 
November 2008).

PARENT-THIRION A., FERNANDEZ MACIAS E., HURLEY J. and VERMEYLEN G. (2007) Forth European Working Conditions Survey. Dublin: European Foundation for the Improvement of Living and Working Conditions.

QUINN, M. (2001) Labour Market Information on the Textiles and Clothing Industry, presented to East Midlands Development Agency Labour Market Skills Forum, 26th September 2001.

SENGUPTA S., EDWARDS P. and TSAI C. (2009) The Good, the Bad and the Ordinary, Work identities in 'Good' and 'Bad' Jobs in the United Kingdom. Work and Occupations, 36(1), pp. 26-55.

[doi:10.1177/0730888408329222]

STRANDH M. (2000) Different Exit Routes from Unemployment and their Impact on Mental Well-being: The Role of the Economic Situation and the Predictability of the Life Course. Work, Employment \& Society, 14(3), pp. 459-479.

UKCES (2010) Employability Skills: A Research and Policy Briefing, UK Commission for Employment and Skills, Briefing Paper Series, March 2010.

VESALAINEN J. and VUORI J. (1999) Job-seeking, Adaptation and Re-employment Experiences of the Unemployed: A 3-year Follow-up. Journal of Community \& Applied Social Psychology, 9(5), pp. 383-394. [doi:10.1002/(SICI)1099-1298(199909/10)9:5<383::AID-CASP530>3.0.CO;2-0]

VIRTANEN M., KIVIMÄKI M., VAHTERA J., ELOVAINIO M., SUND R., VIRTANEN P. and FERRIE J.E. (2006) Sickness Absence as a Risk Factor for Job Termination, Unemployment, and Disability Pension Among Temporary and Permanent Employees. Occupational and Environmental Medicine, 63(3), pp. 212217.

WADDELL G. and BURTON A.K. (2006) Is Work Good for Your Health and Well-being? London: Stationery Office.

WANBERG C.R. (1995) A Longitudinal Study of the Effects of Unemployment and Quality of Reemployment. Journal of Vocational Behaviour, 46(1), pp. 40-54. [doi:10.1006/jvbe.1995.1003]

WARR P. (1987) Work, Unemployment, and Mental Health. Oxford: Oxford University Press.

WARR P. and JACKSON P. (1985) Factors Influencing the Psychological Impact of Prolonged Unemployment and of Re-employment. Psychological Medicine, 15(4), pp. 795-807. [doi:10.1017/S003329170000502X]

WEBER A. and LEHNERT G. (1997) Unemployment and Cardiovascular Diseases: A Causal Relationship? International Archives of Occupational \& Environmental Health, 70(3), pp. 153-160. [doi:10.1007/s004200050201]

WHO (1948) Preamble to the Constitution of the World Health Organisation. adopted by the International Health Conference, New York 19 June - 22 July 1946 edn. <http://www.who.int>: Official Records of the World Health Organisation No. 2, p. 100.

WILSON J. (2007) Old Pit Villages Have to Dig Deep for Jobs. Financial Times, 23 March.

WINTOUR P. (2008) Move to Link Unemployment Benefit to New Work Scheme. Guardian, 20 February.

WISEMAN J. and PARRY E. (2007) Household Survey 2006 East Midlands Region Household Survey Report January 2007. BMG Research Report.

WOOD S. (2008) Job Characteristics, Employee Voice and Well-being in Britain. Industrial Relations Journal, 39(2), pp. 153-168. [doi:10.1111/j.1468-2338.2007.00482.x]

YEANDLE S. (ed.) (2008) Policy for a Change: Local Labour Market Analysis and Gender Equality. Bristol: The Policy Press. 